\title{
First Water-Soluble $\mu$-Nitrido Dimer of Iron Phthalocyanine
}

\author{
Pavel A. Stuzhin, ${ }^{a}{ }^{@}$ Svetlana S. Ivanova, ${ }^{a}$ Ilya Dereven'kov, ${ }^{a}$ Sergey V. Makarov, ${ }^{a}$ \\ Radu Silaghi-Dumitrescu, ${ }^{\mathrm{b}}$ and Heiner Homborg ${ }^{\mathrm{c}}$ \\ ${ }^{a}$ Department of Organic Chemistry, Ivanovo State University of Chemical Technology, RF-153000 Ivanovo, Russia \\ b "Babes-Bolyai" University, RO-400028 Cluj-Napoca, Romania \\ "Institute of Inorganic and General Chemistry, Christian-Albrechts-Universitat, D-24098 Kiel, Germany. \\ ${ }^{\circledR}$ Corresponding authorE-mail: stuzhin@isuct.ru
}

The first water soluble $\mu$-nitridodimer of $\mathrm{Fe}$-phthalocyanine $\mu-N(\mathrm{FeTSP})_{2}$, has been prepared by two alternative routes: (i) by thermolysis of bis-azidocomplex of iron(III) tetrasulfophthalocyanine $\left[\left(N_{3}\right)_{2}\right.$ FeTSPc]-in acetic acid, and (ii) by sulfontion of $\mu$-nitridodiiron bisphthalocyanine $\mu-N(\mathrm{FePc})$, with chlorosulfonic acid.

Keywords: Tetrasulfophthalocyanine, iron complex, $\mu$-nitrido dimer.

The $\mu$-nitrido dimer of Fe-phthalocyanine $\mu-\mathrm{N}(\mathrm{FePc})_{2}$ was first reported and actively studied in the middle of the 1980s. ${ }^{[1,2]}$ Recently it was established that its tert-butyl substituted derivative $\mu-\mathrm{N}\left(\mathrm{FePc}^{t} \mathrm{Bu}_{4}\right)_{2}$ catalyses the oxidation of methane by $\mathrm{H}_{2} \mathrm{O}_{2}$ under very mild conditions $\left(25-60^{\circ} \mathrm{C}\right),{ }^{[3]}$ and then a high catalytic activity was also demonstrated in the oxidation of other organic substrates. ${ }^{[4]}$ It has been shown in theoretical work ${ }^{[5]}$ that the ability of the $\mu$-nitrido moiety to serve as a remarkable charge reservoir and to stabilise the lower spin-states can enhance the catalytic activity of $\mu$-nitrido dimers of Fe-porphyrazines in comparison with the corresponding $\mu$-oxo species. The water-soluble $\mathrm{Fe}^{\mathrm{III}}$ tetrasulfophthalocyanine in its $\mu$-oxo form, $\mu$-O(FeTSPc), catalyses various redox-reactions in aqueous medium. ${ }^{[6]}$ Among $\mu$-nitrido dimers so far only $\mu-\mathrm{N}\left(\mathrm{FePc}^{t} \mathrm{Bu}_{4}\right)_{2}$ and other species well-soluble in organic solvents due to presence of alkyl residues were studied, including alkoxy ${ }^{[7]}$ and alkylsulfony ${ }^{[8]}$ substituted derivatives. We report here the synthesis of the first water-soluble derivative - the $\mu$-nitrido dimer of Fe-tetrasulfophthalocyanine, $\mu-\mathrm{N}(\text { FeTSPc })_{2}$, which was prepared by two alternative routes (Scheme 1).

In the first approach Fe-tetrasulfophthalocyanine, which was prepared by cyclotetramerization of 4-sulfophthalic acid, ${ }^{[9]}$ was used as a starting material. In neutral or basic water solutions this species exists as $\mu$-oxodimer $\mu$-O(FeTSPc $)_{2},{ }^{[6]}$ but its dissolution in acetic acid leads to the monomeric acetate complex (AcO)FeTSPc. This is evidenced by the UVvis spectrum in acetic acid, in which along the $Q$-band at 652 $\mathrm{nm}$ the lower intensity charge-transfer band is seen at 840 $\mathrm{nm}$ (Figure 1, spectrum 2). Such spectrum is characteristic for five-coordinated $\mathrm{Fe}^{\mathrm{III}}$ complexes of porphyrazines ${ }^{[10]}$ and phthalocyanine ${ }^{[11]}$ containing $\mathrm{Fe}^{\mathrm{III}}$ in the intermediate spin
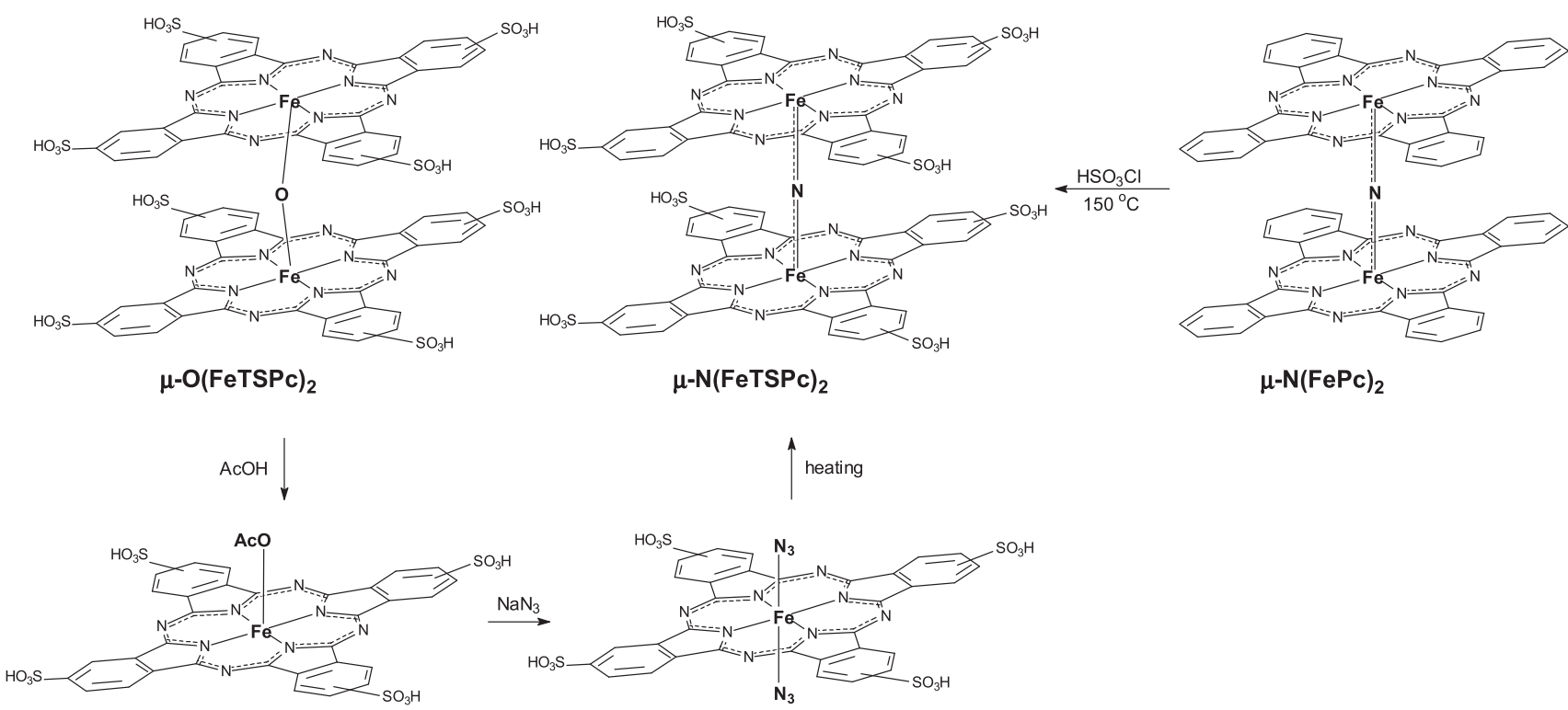

(AcO)FeTSPc

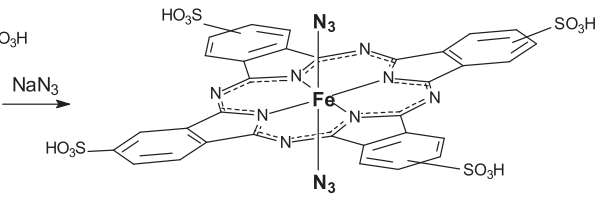

$\left[\left(\mathrm{N}_{3}\right)_{2} \mathrm{FeTSP}^{-}\right.$

Scheme 1. Synthetic routes to $\mu$-nitridodimer of Fe-tetrasulfophthalocyanine, $\mu-\mathrm{N}(\mathrm{FeTSPc})_{2}$. 
state $S=3 / 2$. Thus for $[(\mathrm{Cl}) \mathrm{FePc}]$ the $Q$-band at $655 \mathrm{~nm}\left(\pi-\pi^{*}\right.$ transition) is accompanied by a charge transfer band $\left(\pi-\mathrm{d}_{\pi}\right)$ at $832 \mathrm{~nm} \cdot{ }^{[11]}$ Addition of azide $\left(\mathrm{NaN}_{3}\right.$ or $\left.\mathrm{HN}_{3}\right)$ leads to formation of a six-coordinated bisazido complex [ $\left.\left(\mathrm{N}_{3}\right)_{2} \mathrm{FeTSPc}\right]^{-}$which can be followed by disappearance of the absorption bands of the pentacoordinated acetate complex at 652 and $840 \mathrm{~nm}$ and the appearance of a new very intense band at $673 \mathrm{~nm}$ (Figure 1, spectrum 3). Six-coordinated pseudohalide complexes of $\mathrm{Fe}^{\mathrm{III}}$-phthalocyanine $\left[(\mathrm{X})_{2} \mathrm{FePc}\right]^{-}$exhibit similar spectral features with the $Q$-band at $670-690 \mathrm{~nm}$. Refluxing of the solution of the bisazido complex $\left[\left(\mathrm{N}_{3}\right)_{2} \text { FeTSPc }\right]^{-}$leads to its thermolysis with formation of the $\mu$-nitrido dimer, $\mu-\mathrm{N}\left(\right.$ FeTSPc) ${ }_{2}$ (Figure 1, spectrum 4), similarly as in the case of bisazido complexes of unsubstituted $\mathrm{Fe}^{\mathrm{III}}$-phthalocyanine. [2]

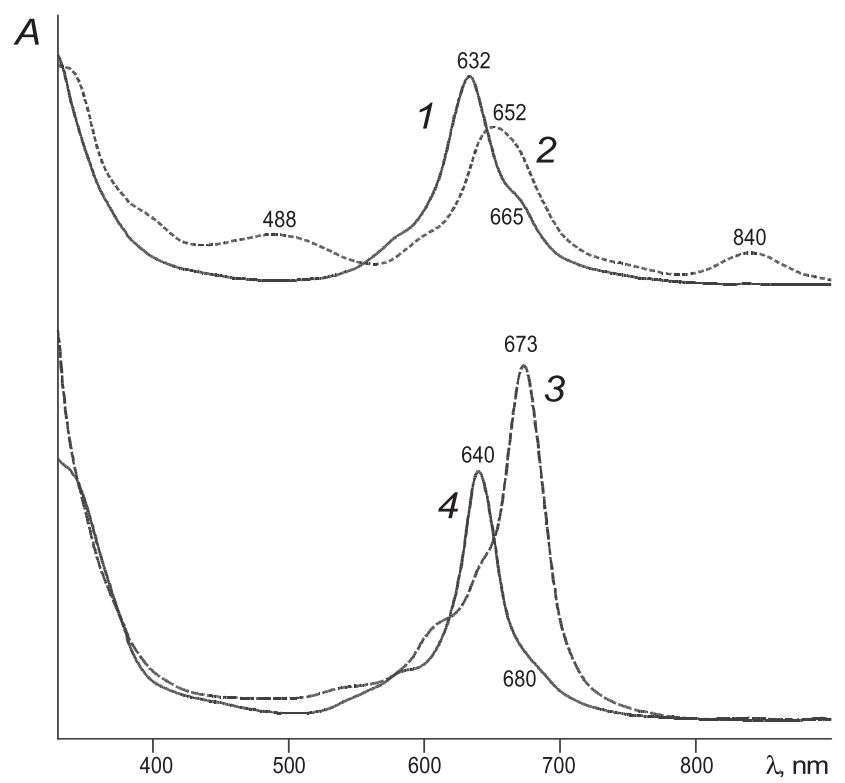

Figure 1. UV-Vis spectra of $\mu$-oxo dimer $\mu-\mathrm{O}(\mathrm{FeTSPc})_{2}$ in water (1), acetate complex (AcO)FeTSPc formed in acetic acid (2); its conversion to bis azido complex $\left[\left(\mathrm{N}_{3}\right)_{2} \mathrm{FeTSPc}^{-}\right.$(3)after addition of $\mathrm{NaN}_{3}$, and to $\mu$-nitrido dimer $\mu$-N(FeTSPc) $)_{2}$ (4) upon heating.

The second approach is based on our finding that the $\mu$-nitrido dimer of Fe-phthalocyanine $\mu-\mathrm{N}(\mathrm{FePc})_{2}$, prepared as described elsewhere, ${ }^{[1, a, 2]}$ unlike the $\mu$-oxo-dimer $\mu-\mathrm{O}(\mathrm{FePc})_{2}$, is very stable even in very strongly acidic media and can be chlorosulfonated with hot $\mathrm{HSO}_{3} \mathrm{Cl}(4 \mathrm{~h}$ at $\left.150^{\circ} \mathrm{C}\right)$. After overnight staying of the reaction mixture the chlorosulfonic derivative $\mu-\mathrm{N}\left(\mathrm{FePc}\left(\mathrm{SO}_{2} \mathrm{Cl}\right)_{4}\right)_{2}$ was isolated by pouring on ice and then hydrolysed with water at $80^{\circ} \mathrm{C}$ to give $\mu-\mathrm{N}(\mathrm{FeTSPc})_{2}$. Treatment of the sulfochloride $\mu-\mathrm{N}\left(\mathrm{FePc}\left(\mathrm{SO}_{2} \mathrm{Cl}\right)_{4}\right)_{2}$ with dibutylamine gives the sulfamide derivative $\mu-\mathrm{N}\left(\mathrm{FePc}\left(\mathrm{SO}_{2} \mathrm{NBu}_{2}\right)_{4}\right)_{2}$. Elemental analysis and ESI mass-spectroscopy show the presence of four sulfonyl groups per Fe-phthalocyanine unit.

The UV-Vis spectrum of the obtained $\mu$-nitrido dimer $\mu-\mathrm{N}(\mathrm{FeTSPc})_{2}$ in acetic acid contains a broadened $Q$-band with a maximum at $640 \mathrm{~nm}$ and a shoulder at $680 \mathrm{~nm}$ (Figure 1 , spectrum 4). The spectrum in water is shown in Figure 2 (left panel). Such spectral pattern is typical for single-atom $\mu$-bridged dimeric Fe-phthalocyanines with exciton coupling between two adjacent $\pi$-chromophores. In comparison with the $\mu$-oxodimer $\mu$-O(FeTSPc), the $Q$-band and the Soret bands in the UV-vis spectrum of $\mu-\mathrm{N}(\mathrm{FeTSPc})_{2}$ are bathochromically shifted $(632 \rightarrow 640$ and $326 \rightarrow 336 \mathrm{~nm}$, respectively, Figure 2, left panel). Interestingly, the maximum of the $Q$-band in $\mu-\mathrm{N}(\mathrm{FeTSPc})_{2}$ has a similar position to that observed in dichlorometane solutions of alkylsulfonyl substituted derivatives $\mu-\mathrm{N}\left(\mathrm{FePc}\left(\mathrm{SO}_{2} \mathrm{Alk}\right)_{4}\right)_{2}$ (Alk $=$ tertbutyl, hexyl, $\left.\lambda_{\mathrm{O}} \sim 638 \mathrm{~nm}\right)$ and dibutylsulfonylamide $\mu-\mathrm{N}\left(\mathrm{FePc}\left(\mathrm{SO}_{2} \mathrm{NBu}_{2}\right)_{4}\right)_{2}\left(\lambda_{Q}=634 \mathrm{~nm}\right)$. The difference in the electron-withdrawing properties of various sulfonyl groups is relatively small and the peripheral substituents in the phthalocyanine macrocycle have only weak influence on the spectral properties, which are more sensitive to the coordination mode and electronic structure of the metal center. The close position of the $Q$-band for the obtained sulfonated $\mu$-nitrido dimer of Fe-phtalocyanine ( $\sim 635-640$ $\mathrm{nm})$ with the non-oxidised $\mu$-nitrido dimers bearing other sulfonyl substituents is indicative of their similar electronic structure.

The $\mu$-nitrido dimers of Fe-phthalocyanine can contain two equivalent iron atoms either in the oxidation state +3.5 $\left(\mathrm{Fe}^{\left.\mathrm{III} / 2 \cdots \mathrm{N} \cdots \mathrm{Fe}^{\mathrm{III} / 2}\right)}\right.$ or $+4\left(\mathrm{Fe}^{\mathrm{IV}}=\mathrm{N}^{+}=\mathrm{Fe}^{\mathrm{IV}}\right) \cdot{ }^{[1,2]}$ In the case of the unsubstituted derivative $\mu-\mathrm{N}(\mathrm{FePc})_{2}$ the oxidation to cationic species $\left[\mu-\mathrm{N}(\mathrm{FePc})_{2}\right]^{+}$containing two $\mathrm{Fe}^{\mathrm{IV}}$ occurs already at $E^{1 / 2}=0.00 \mathrm{~V}$ and requires very mild oxidation agents such as ferrocenium cation, tetracyanoquinodimethane ${ }^{[1]}$ or even iodine, while stronger oxidants, e.g. bromine, nitric acid or trifluoroacetic acid in air, lead to further oxidation involving macrocycle ${ }^{[2]}$ yielding red-brown coloured complexes of $\mathrm{Fe}^{\mathrm{IV}}$ with phthalocyanine cation-radical - $\left[\mu-\mathrm{N}\left((\mathrm{X}) \mathrm{FePc}^{+}\right)_{2}\right]^{+}(\mathrm{X})$ $\left(\mathrm{X}=\mathrm{Br}, \mathrm{CF}_{3} \mathrm{COO}^{-}, \mathrm{NO}_{3}^{-}\right)$. Upon oxidation of the $\mu$-bridge from $\left(\mathrm{Fe}^{\left.\mathrm{III} / 2 \cdots \mathrm{N} \cdots \mathrm{Fe}^{I I I / 2}\right)}\right)$ to $\left(\mathrm{Fe}^{\mathrm{IV}=}=\mathrm{N}^{+}=\mathrm{Fe}^{\mathrm{IV}}\right)$ the $Q$-band maximum is shifted bathochromically by $10-20 \mathrm{~nm},{ }^{[1 b, 8}$ while further oxidation of the macrocycle leads to red-brown species $^{[2]}$ due to appearance of absorption in the $500-550 \mathrm{~nm}$ region characteristic for cation-radicals.

We have studied the action of oxidants on the spectral properties of the obtained $\mu$-nitridodimer of Fetetrasulfophthalocyanine. In the presence of hydroperoxide $\left(\mathrm{H}_{2} \mathrm{O}_{2}\right.$ in basic medium) no changes were observed in its UV-vis spectrum in aqueous solution. Addition of bromine to its solution in acetic acid leads only to some broadening of the $Q$-band, while the position of its maximum remains changed. The $Q$-band at $\sim 635-640 \mathrm{~nm}$ in $\mu-\mathrm{N}(\text { FeTSPc })_{2}$ can be associated with the presence of the $\left(\mathrm{Fe}^{\left[11 / 2 \cdots \mathrm{N} \cdots \mathrm{Fe}^{I I I 1 / 2}\right)}\right.$ bridge, since in the cationic oxidised species, containing $\left(\mathrm{Fe}^{\mathrm{IV}}=\mathrm{N}^{+}=\mathrm{Fe}^{\mathrm{IV}}\right)$, it should be observed at longer wavelength (650-665 nm). Thus, for the oxidised alkylsulfonyl derivatives $\left[\mu-\mathrm{N}\left(\mathrm{FePc}\left(\mathrm{SO}_{2} \mathrm{Alk}\right)_{4}\right)_{2}\right]^{+}$the $Q$-band is shifted from 638 to $647-657 \mathrm{~nm},{ }^{[8]}$ and the addition of $\mathrm{Br}_{2}$ to solution of sulfamide derivative $\mu-\mathrm{N}\left(\mathrm{FePc}\left(\mathrm{SO}_{2} \mathrm{NBu}_{2}\right)_{4}\right)_{2}$ in $\mathrm{CH}_{2} \mathrm{Cl}_{2}$ shifts the $Q$-band from 634 to $664 \mathrm{~nm}$ and broadens it. The electron-withdrawing sulfonyl groups presumably stabilise the phthalocyanine macrocycle to oxidation by bromine.

The ESR spectrum of $\mu-\mathrm{N}(\mathrm{FeTSPc})_{2}$ aqueous solution (Figure 2, right panel) confirms the presence of the $\left(\mathrm{Fe}^{\mathrm{III} / 2 \cdots \mathrm{N} \cdots}\right.$ $\left.\mathrm{Fe}^{\mathrm{III} / 2}\right)$ bridge. It contains the characteristic triplet at $g_{\perp}=2.13$, which is typical for $\mu$-nitrido dimers of Fe-porphyrins ${ }^{[12]}$ and $\mathrm{Fe}$ porphyrazines ${ }^{[13]}$ and originates from the hyperfine interaction of the unpaired electron with ${ }^{14} \mathrm{~N}$ nucleus on the $\mu$-nitrido-bridge $\left(A^{\mathrm{N}}{ }_{\perp}=2.60 \mathrm{mT}\right)$. The complicated ESR pattern in the $\mathrm{g} \sim 1.9-2.9$ 


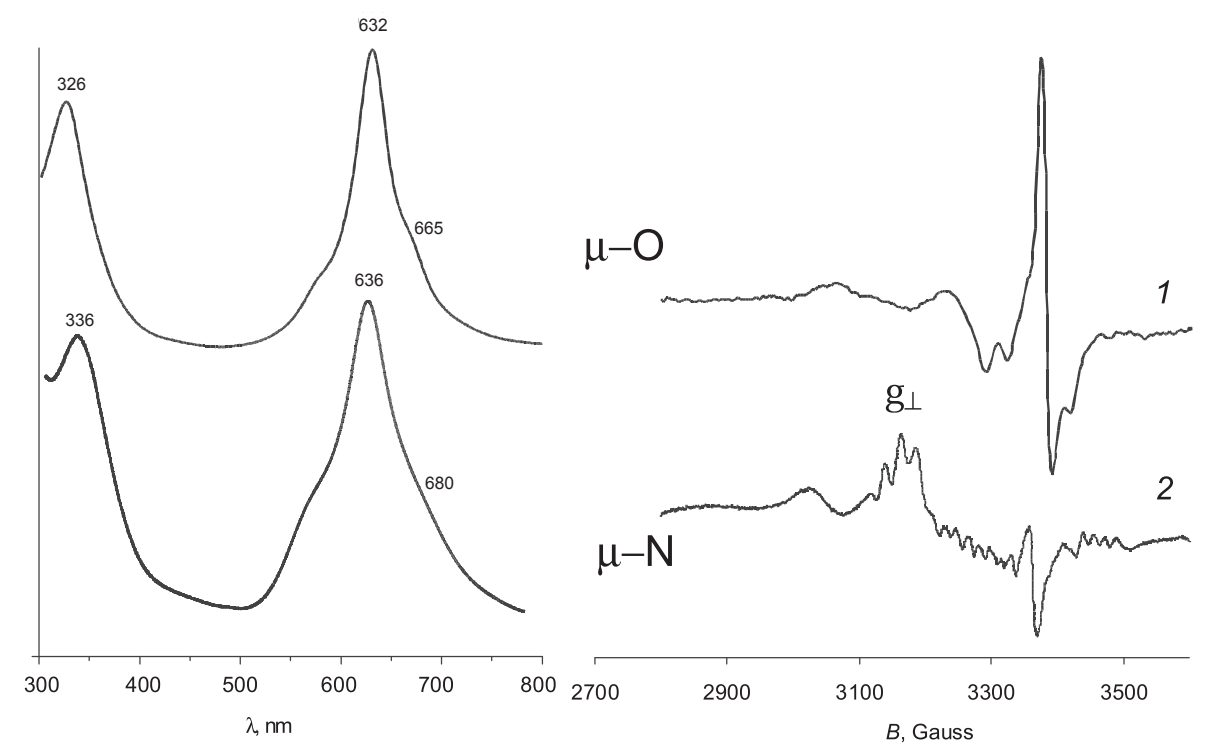

Figure 2. UV-Vis (left) and ESR (right) spectra of $\mu$-oxo (1) and $\mu$-nitrido (2) dimers of Fe-tetrasulfophthalocyanine in water.

region might be connected with the additional interaction with the nitrogen atoms of the phthalocyanine macrocycle and coordination of oxygen as was observed for $\mu$-nitrido dimer of Feporphyrazine. ${ }^{[13]}$ The ESR spectrum exhibits also minor signals of the monomeric impurities, containing $\mathrm{Fe}^{\mathrm{III}}$ in the spin states $S=1 / 2$ and $3 / 2\left(g_{3}\right.$ at 2.3 and $g_{\perp} \sim 4.3$, respectively), which can not be seen in UV-Vis spectrum

The value of the magnetic moment of $\mu-\mathrm{N}(\text { FeTSPc })_{2}$ in water solution $\mu_{\text {eff }}=2.14 \mu_{\mathrm{B}}$ at $298 \mathrm{~K}$ (Evans method) also corresponds to the value expected for a system with one unpaired electron and is consistent with the data reported for the dimeric $\mu$-nitrido Fe-complexes of other tetrapyrrolic macrocycles $-\mu-\mathrm{N}(\mathrm{FePc})_{2}\left(\mu_{\text {eff }}=2.13 \mu_{\mathrm{B}}\right),{ }^{[1]}$ Fe-octaphenylporphyrazine $\left(2.24 \mu_{\mathrm{B}}\right)^{[13]}$ and Fe-tetraphenylporphine $\left(\mu_{\text {eff }}=2.04 \mu_{\mathrm{B}}\right) .^{[14]}$

In the NMR spectrum, the aromatic protons of the benzene rings are observed as overlapping multiplets in the region typical for diamagnetic phthalocyanines (7.6-8.7 ppm), implying negligible delocalization of the unpaired electron from the $d_{z^{2}}$ orbital onto the phthalocyanine macrocycle. ${ }^{[15]}$

In conclusion, we have prepared the $\mu$-nitrido dimer of Fe-tetrasulfophthalocyanine, $\mu-\mathrm{N}(\mathrm{FeTSPc})_{2}-$ the first watersoluble $\mu$-nitrido dimer, and provide evidence that it contains

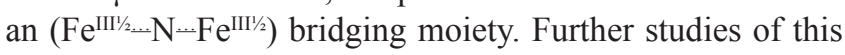
complex, including its redox properties and catalytic activity in aqueous solution, are in progress.

Acknowledgements. This work was supported by the Russian Foundation of Basic Research (grant Nr 12-03-00563).

\section{References}

1. (a) Goedken V.L., Ercolani C. J. Chem. Soc., Chem. Comm. 1984, 378-379. (b) Bottomley L.A., Gorce J.-N., Goedken V.L.,
Ercolani C. Inorg. Chem. 1985, 24, 3733-3737. (c) Ercolani C., Gardini M., Pennesi G., Rossi G., Russo U. Inorg. Chem. 1988, 27, 422-427.

2. Kennedy B.J., Murray K.S., Homborg H., Kalz W. Inorg. Chim. Acta 1987, 134, 19-21.

3. Sorokin A.B., Kudrik E.V., Bouchu D. Chem. Commun. 2008 2562-2564.

4. Kudrik E.V., Sorokin A.B. Macroheterocycles 2011, 4, 154 160 (http://dx.doi.org/10.6060/mhc2011.3.02).

5. Silaghi-Dumitrescu R., Makarov S.V., Uta M.-M., Dereven'kov I.A., Stuzhin P.A. New J. Chem. 2011, 35, 1140-1145.

6. (a) Hadasch A., Sorokin A., Rabion A., Meunier B. New J. Chem. 1998, 22, 45-51. (b) Beyrhouty M., Sorokin A.B., Daniele S., Hubert-Pfalzgraf L.G. New J. Chem. 2005, 29 , 1245-1248. (c) Kudrik E.V., Makarov S.V., Zahl A., van Eldik R. Inorg. Chem. 2005, 44, 6470-6475.

7. Kudrik E.V., Afanasiev P., Bouchu D., Sorokin A.B. J. Porphyrins Phthalocyanines 2011, 15, 583-591.

8. (a) İşci Ü., Afanasiev P., Millet J.-M.M., Kudrik E.V., Ahsen V., Sorokin A.B. Dalton Trans. 2009, 7410-7420. (b) Afanasiev P., Bouchu D., Kudrik E.V., Millet J.-M.M., Sorokin A.B. Dalton Trans. 2009, 9828-9836.

9. Weber J.N., Busch D.H. Inorg. Chem. 1965, 4, 469.

10. Stuzhin P.A. Macroheterocycles 2009, 2, 114-129 (http://macroheterocycles.isuct.ru/sites/default/files/ MHC2009t02n02_114-129_0.pdf).

11. (a) Kalz W., Homborg H. Z. Naturforsch. 1983, 38b, 470-484. (b) Kennedy B.J., Murray K.S., Zwack P.R., Homborg H., Kalz W. Inorg. Chem. 1986, 25, 2539-2545.

12. Bottomley L.A., Garrett B.B. Inorg. Chem. 1982, 21, 12601263.

13. Stuzhin P.A., Latos-Grazynski L., Jezierski A. Transition Met. Chem. 1989, 14, 341-346.

14. Summerville D.A., Cohen I.A. J. Am. Chem. Soc. 1976, 98, 1747-1752.

15. Tatsumi K., Hoffmann R. J. Am. Chem. Soc. 1981, 103, 33283341

Received 08.03.2012

Accepted 19.05.2012 